\title{
Wheat Production in India: Technologies to Face Future Challenges
}

\author{
Rajbir Yadav \\ Division of Genetics, Indian Agricultural Research Institute \\ Pusa Campus, New Delhi- 110 012, India \\ Tel: 95-11-2584-1481Ｅ-mail: rajbiryadav@yahoo.com \\ S S Singh \\ Directorate of Wheat Research, Karnal (Haryana), India \\ Neelu Jain (Corresponding author) \\ Division of Genetics, Indian Agricultural Research Institute \\ Pusa Campus, New Delhi- 110 012, India \\ Tel: 95-11-2584-1481_E-mail: neelu_jain25@yahoo.com \\ G P Singh \\ Division of Genetics, Indian Agricultural Research Institute \\ Pusa Campus, New Delhi- 110 012, India \\ Tel: 95-11-2584-1481Ｅ-mail: dwrpartap@gmail.com \\ K V Prabhu \\ Division of Genetics, Indian Agricultural Research Institute \\ Pusa Campus, New Delhi- 110 012, India \\ Tel: 95-11-2584-1481Ｅ-mail: kvinodprabhu@rediffmail.com
}

\begin{abstract}
To meet the growing demands under the constrains of depleting natural resources, environmental fluctuation and increased risk of epidemic outbreak, the task of increasing wheat production has become daunting. The euphoria generated by first green revolution is very quickly subsiding and the second generation problems are becoming more intense with each passing year. The factors responsible for first green revolution seem to be exhausting rapidly and there is immediate need to develop the technologies which can not only increase the wheat production but also sustain at higher level without adversely affecting the natural resources. More investment on germplasm improvement, conservation agriculture including breeding for varieties adaptive to conservation agriculture, hybrid wheats, broadening the genetic base of the varieties at farmers level, wide scale utilization of alien translocations in the breeding programme along with integration of marker assisted selection and other innovative approaches with traditional breeding methods are some of the technologies which can yield dividend in the coming years.
\end{abstract}

Keywords: Wheat, Breeding, Technologies, Sustainable, Production conservation agriculture, Heat tolerance, Germplasm improvement

\section{Introduction}

Wheat is one of the most important staple food crops grown over 200 mha in the range of environment throughout the world with an annual production likely to reach more than 650 million metric tons in 2009-10. Despite remarkable growth in food production, the risks were exposed by food crisis in the recent years. Therefore, wheat production must continue to increase by $2 \%$ annually, more particularly in developing world including south-east Asia until 2020 to meet future demands imposed by population and prosperity growth 
(Reynolds et al. 2008). This challenge will probably be further compounded by reduced water availability (Shiklomanov \& Rodda 2003), increased temperature due to global warming (Fischer et al. 2002), new races of pathogen and pest besides decrease in public sector investment in agriculture and rural affairs (Falcon \& Naylor 2005). Commercially cultivated wheat is basically of two types i.e durum wheat (Triticum turgidum) and bread wheat (Triticum aestivum) that differ in their genetic complexity, adaptation as well as use. A wide range of products are now made and consumed worldwide from both types of wheat.

India achieved remarkable progress in wheat production during the last 4 decades and is the second largest wheat producer in the world. In India, scientific plant breeding probably began in the first decade of the 20th Century (Jain \& Byerlee 1999) and pure line selection by Howard and Howard from the local landraces resulted in several wheat varieties like NP 4. This was followed by period (1920-1940) when lot of exotic material was used in crossing and several high-yielding varieties of the $\mathrm{Pb}$ and NP series were developed. The higher incidence of rusts, particularly black and brown rusts in cultivated wheat, forced breeders to incorporate disease resistance in the breeding material, and notably improved material such as NP809 (resistant to all three rusts) was developed in 1954. Despite all this progress, average wheat productivity was quite low up to 1964-65. In 1962, Dr B.P. Pal and Dr M.S. Swaminathan observed photo-thermo insensitive, dwarf, input responsive wheat lines in the material initially developed by Dr N E Borlaug and supplied by the United States Department of Agriculture (USDA) which laid the foundation for the so-called 'green revolution'. The selection of amber-grained, input-responsive, high-yielding varieties such as PV18, Kalyan Sona, Sonalika, Chhoti Lerma, and Safed Lerma, and their faster adoption by farmers, led to unparalleled growth in wheat production in India and by 1970, wheat production in India reached $20 \mathrm{Mt}$. The path of progress was further cemented by the release and cultivation of varieties like HD 2009, WL 711, WH 147, UP 262, Lok 1, HD 2285, HD 2329. This was again followed by period of despair and frustration when, researchers failed to breed over and above HD 2329 for a very long period. Veery based material again came to the rescue of the country and many $1 \mathrm{~B} / 1 \mathrm{R}$ based varieties like WH 542, PBW 343, and PBW 373 with improved disease resistance, productivity, and response to more intensive cropping systems, were released for cultivation. During the last 40 years, $\sim 312$ wheat varieties have been released in India's six wheat zones. The continuous efforts of breeders and other wheat workers led to more sharp gain in total factor productivity in the post Green revolution period than in Green revolution era.

The momentum of growth in wheat production could not keep pace with demand in the last 5 years or so. Total factor productivity (TFP) and yield growth have slowed in most productive wheat belt of India (Rejesus et al. 1999). This along with declining land quality, declining investment and increased intellectual property protection has made the task of increasing the production more complicated. To ensure gradual gains in wheat production with a shrinking land base, breeding wheat cultivars with increased grain yield potential, enhanced water use efficiency, heat tolerance, end-use quality, and durable resistance to important diseases and pests can contribute to meeting at least half of the desired production increases. The remaining half must come through better agronomic and soil management practices and incentive policies. In order to meet the daunting task of increasing yield potential in a sustainable way, the breeding efficiency has to be improved significantly (Slafer et al. 2005). In 1990, Swaminathan used the term "Evergreen Revolution" to emphasize the need for enhancing productivity without harming the environment. According to him, in densely populated countries like India, China, and Bangladesh, production increase has to come under diminishing arable land, irrigation water and increasing biotic and abiotic stresses (Swaminathan 2006).

\section{Why is there need of paradigm shift in breeding strategies?}

In the last 50 years or so, major emphasis for wheat breeding has been on yield potential gains, resistance against biotic stresses, and management of abiotic stresses particularly drought and heat. Yield potential in wheat increased globally including both developing as well as developed countries. The green revolution in Indian subcontinent was primarily based on three components i.e. high yielding dwarf varieties, increased use of fertilizer and addition of irrigation facilities. All these three components now seem to be exhausting very fast.

- Adoption of high yielding variety is complete. Most of the farmers in India at present are now using the high yielding varieties, though replacement with new varieties seems to be some issue in North Eastern Plain zone where a product of first phase of green revolution (UP 262) is still under cultivation over a significant area.

- Use of fertilizer is fastly approaching the optimum level. Farmers in Northwestern plain zone are using more than recommended dose of the fertilizer and therefore there appears to be no scope for the improvement of productivity through adoption of fertilizer. However, the distortion in the ratio of $\mathrm{N}$ and $\mathrm{P}$ is the cause of worry and can have long-term negative effect on productivity. 
- Wheat in India is now grown in irrigated area in more than 87 per cent of area and scope of its further expansion in major wheat growing belt seems to be very remote. Increase in productivity through bringing more area under irrigation seems to be exhausted.

As neither of the above component can be the driver of growth in production in future, the gain has to come from drastic modification in the breeding strategies. None of the varieties released for north-western plain zone in the recent past is significantly superior to prevailing variety PBW 343 and therefore release of newer varieties has only added to the diversity and minimized the threat perception of losses due to disease but can not be the vehicle for growth.

\section{Technological needs to address the challenges before Indian wheat breeding programme}

Indian wheat breeding programme is facing the challenge of stagnating productivity and second generation problems of rice-wheat cropping system, increasing heat in north-eastern plain along with other associated problems, declining profit due to increase in cost of production and fear of epidemic out break due to increased genetic uniformity at the farmers field. These challenges can be handled through appropriate technological developments which have been briefly discussed here in this paper.

\subsection{Germplasm improvement is still paramount}

The evolution of hexaploid wheat of Triticum aestivum L. (AABBDD) is well known among the wheat researchers as the tetraploid wheat (Triticum turgidum L) (AABB) first originated from the species of A genome (Triticum urartu Tumanian ex Gandilyan) (Dvorak et al. 1993), and B genome ancestor Aegilops speltoides Tausch (SS) (Terachi et al. 1988), and then tetraploid wheat hybridizing under natural condition with D genome donor i.e. Aegilops tauschii Coss. (Kihara 1944). The diversity available in D genome of cultivated hexaploid wheat is very limited in comparison to what is available in $\mathrm{D}$ genome of diploid species (Dvorak et al. 1998). Similarly tetraploid wheat also evolved from limited population of Triticum dicoccoides and therefore, a huge amount of untapped useful diverse genes are available in these ancestral species. Beside these ancestral species, alien species of wheat forms another reservoir containing many useful genes. The green revolution was set rolling by the exchange of germplasm from Korea to Japan and then to USA and CIMMYT Mexico in the form of Norin 10 variety as a source of dwarfing gene. Use of winter wheat crosses with spring wheat at CIMMYT resulted in the development of Veery and Attila wheats, which out yielded the prevalent cultivars by 15 per cent. The dissemination of these germplasm lines through international co-operation resulted in the identification of number of high yielding varieties of wheat like PBW 343, PBW 373 (basically Attila developed by CIMMYT and picked up by PAU scientist) and WH 542. The development of Attila represents the unique combination of genetic resources from Oregon (USA), France, Mexico (CIMMYT), and India. The role of international collaboration in wheat improvement therefore, is well known and is still relevant. It will be so in the future and the crux of this collaboration has been the exchange of seed. Most of the researchers feel the yield potential of wheat is far from exhausted and therefore again needs renewed efforts and international cooperation.

Transferring the valuable diversity available in wild relatives can provide much needed germplasm for further yield improvement. Synthetic wheat developed by crossing the Triticum durum with many of these wild relatives needs to be involved in crossing at large scale with indigenous high yielding wheat varieties. Synthetic wheats are harbinger of agronomically important traits like resistance to Karnal bunt, Helminthosporium blight, heat and drought tolerance. Broader introgression of synthetic wheat has already shown its impact (Ogbonnaya et al. 2005) and therefore involvement of these synthetic wheats or their backcross derivatives can pay dividend.

\subsection{Conservation agriculture to beat the heat and increase the profits}

Under uncertain future regarding the gain in productivity in north-western plain zone of India by increasing yield potential, the farmer's income in this part of country can be raised through crop management techniques which significantly reduces the cost. These management techniques however should be sustainable over a long period of time. Intensive agriculture as being practiced though increased the production but simultaneously degraded the natural resources and therefore is not sustainable for a very long period of time. Sustainable agriculture on the other hand maintains ecological equilibrium by encouraging naturally regenerating processes like nitrogen fixation, nutrient cycling, soil regeneration, and protection of natural enemies of pest and diseases as well as the targeted use of inputs. Conservation agriculture can help in achieving the goal of sustainable agriculture as it is dependent upon the practices that support high productivity without degrading the environment and endangering the biodiversity.

Conservation agriculture envisages significant reduction in tillage and if possible zero tillage in most of the cropping systems and adequate retention of crop residue to improve physical, chemical and biological properties 
of the soil. Raised bed planting is one of the techniques which was initiated by CIMMYT researchers in Yaqui Valley in northwest Mexico and it spreaded to more than 20 countries, however, this became feasible only when multi-crop/multi-use implements become available (Hobbs 2001). Permanent raised bed with furrow in between the beds will not only save the water but will comprise essentially all the components of conservation agriculture. Encouraging results have also been obtained in increasing productivity in Turkey by foliar application of $\mathrm{Zn}$ due to its essential role in detoxification of reactive oxygen species. Reduced tillage which is one of the important component of conservation agriculture is becoming important in wheat growing areas of world particularly in rice-wheat cropping system which is at present largest wheat based cropping system covering about 24 mha of area in Asian tropics (Hobbs 2001; Joshi et al. 2007). With declining return and stagnating productivity in this system, question has been raised about sustainability (Hobbs \& Morris 1996). Conservation tillage is spreading rapidly in the agricultural world, and probably now covers more than 100 million ha. This cost saving technology is widely employed in South America, North America and Australia, and is now gaining ground in Europe and South Asia.

Conservation agriculture does not involve the reduced tillage alone but is a complete philosophy which involves many components including the varieties suited for conservation agriculture. Number of changes introduced into chemical, physical and biological properties by the tillage operation alone and the presence of significant amount of tillage $\mathrm{x}$ genotype interaction suggests for specific genotypic requirement of these production conditions (Sayre 2002; Trethowan \& Reynolds 2005). Faster root growth exudates promotes more beneficial rhizosphere microflora, or modified shoot responses as possible mechanisms for the superior growth of Vigor 18 (Watt et al. 2005). The vigour therefore can be the important characteristics of such genotypes. Varieties are bred many times to over come the problem fostered by essentially unhealthy agricultural systems. Monoculture crop and monoculture varieties as PBW 343 in India grown continuously over the years has helped in increasing the proportion of its virulent races like 78S 84 of yellow rust in the nature. Conservation agriculture practices have many constraints that need to be solved. One of the biggest constraints is that most of the practices of conservation agriculture are performed with the varieties suited for conventional agriculture and therefore, the result of most of the experiments may not be true. Conservation agriculture therefore besides many other things require the genotype that suits to such kind of practices. Besides agronomic components like tillage, residue management and rotation practices, genotypes suited to conservation agriculture are also important. Number of studies (Slafer et al.1999; Araus et al. 2002) have been conducted which shows that improved adaptiveness can raise both yield potential as well as yield under environmental constrains. Development of genotypes adapted to conservation agriculture practices including those improving water use efficiency will require rigorous and coordinated research efforts.

\subsection{Production of commercially viable hybridization technologies to combat the environmental fluctuations}

Research on development of hybrid wheat could not yield fruitful result for private sector companies in USA and other countries in the past. Research efforts on this aspect, globally has been negligible in the recent past, however, there is renewed interest in the development of hybrids through chemical hybridizing agent, and cytoplasm male sterility routes. Evidences indicates the presence of 15-20 per cent of heterosis, which if exploited through effective seed production techniques can provide further jump in yield gain. Optimization of genetic diversity between female and male gene pools has been the major strategy in breeding hybrids. As hybrid seed production is not economical, their adoption by the farmers due to higher seed cost pose a great challenge to the scientific community. Hybrid seeds should be made cost-effective by decreasing the seeding rate, increasing the yield levels and alteration in planting technologies. Heterosis based on yield component like tiller number can significantly reduce the seed rate but such hybrids at commercial scale are not available. Identification of seed production conditions can also economize the hybrid seed production to a great extent. To make hybrid seed marketing a viable option, improved seed production technologies with related floral characteristics should be produced. Heterosis for characters adapted to stress environments has been successfully achieved in the past and could enable the breeders to develop varieties for better performance under stress. Hybrid wheats may be adopted even in less-favorable, semi-subsistence environments provided there are efficiency gains in seed production and distribution systems (Matuschke et al. 2007). A significant portion of wheat growing areas in India comprising southern Haryana, whole Rajasthan, Madhya Pardesh, Gujrat, eastern Uttar Pardesh and part of Bihar faces abiotic stresses particularly terminal heat and water deficiency during reproductive phase. In most of these areas except Haryana, the yield gain due to green revolution has been limited. World over the progress with empirical breeding has been less in the areas affected by abiotic stress largely due to uncertainty in occurrence and plant growth stage affected. Hybrid wheat with specific adaptation to the climatic conditions of the above area can significantly improve the yield realization due to higher yield responsiveness and better 
stability in comparison to pure line varieties. Being a self pollinated crop, there will be always a competition between hybrid wheat and pure line varieties in wheat and therefore, any investment for the gain in the future through these technologies should also consider the gain in future through pure line varieties. Hybrid development programme should, therefore have very strong linkage with varietal improvement programme for utilization of improved genetic base as a parent and to provide an edge over the pure line varieties.

\subsection{Changing the genetic architecture of wheat plant}

According to Evans (1993), potential yield of a variety can be obtained when it is grown in its adapted environments with no limitation of nutrients and water stresses and pest and diseases effectively controlled. The identification of the fact that plant type of IR 8 is itself a limiting factor for further yield increase in rice led to the establishment of a new plant type concept in IRRI. The continuous effort of a team led by Dr Khush at IRRI, resulted in the number of high yielding lines of so called new plant type (NPT) with long panicle that broke the yield barrier of 10 tones per ha. The success of NPT revived the similar hope in wheat to break the barrier imposed by PBW 343. Long spike with very stiff and strong stem has always been the trait for designing the new plant type. Singh et al. (2005) reported new lines of wheat like DL 1266-5 with dark green broad leaf and robust stems with slightly improved kernel weight of 45-50 g and number of grains/spike varying from 90-100 that out yielded PBW 343 at Delhi. This new architectural type widely dubbed as super wheat could not succeed largely as it was not integrated with prevailing agronomic practices and required further improvement for its adoptions by the farmers. A number of lines with Lr9 and Lr19 gene combinations have been developed through similar type of plant material and can be a good material to work upon for further improvement. International centres like CIMMYT have also developed similar material by crossing Tetrastichon (from Yugoslavia), Morocco (from Morocco), Agrotriticum (from Canada), and Polonicum (tetraploid branched wheat from Poland) with high-yielding parents from CIMMYT's spring wheat program (Rajaram et al. 2002). Further improvement can also be obtained by changing the characters like stomatal aperture (Condon et al. 2005), related traits like flag leaf stomatal porosity, canopy temperature, carbon isotope discrimination ( $13 \mathrm{C})$ for photosynthetic capacity, and oxygen isotope $\left({ }^{18} \mathrm{O} /{ }^{16} \mathrm{O}\right)$ for stomatal conductance.

\subsection{Broadening genetic base with respect to disease resistance}

A large number of varieties have been released in India but genetic diversity at the farmer's field level is very limited. There are number of disease and insect-pest which cause losses in yield in different agro-ecological system and their comprehensive list can be found in many compendiums (Wilcoxson \& Saari, 1996; Duveiller et al. 1997). Monitoring team for the North-western plain zone visited number of research stations and found very high incidence of yellow rust in 2008-09 in many districts of Punjab. The high incidence could not cause much reduction in yield largely, because it appeared late in the season. With no genetic diversity at the farmers field due to continuous track of single variety PBW 343 and presence of yellow rust races namely $78 \mathrm{~S} 84$ and $46 \mathrm{~S}$ 119 which are able to infect and multiply on PBW 343, we are short of only favorable climatic condition for disease development for an epidemic outbreak. As this variety alone covers near about $7 \mathrm{mha}$, the losses would have been huge. The researchers generally project the high potential losses and actual losses at the farmer's field are much lower. Despite this, the risk should never be undermined, particularly if we have the technologies or methodology to develop technologies to minimize the risk.

In the absence of suitable disease data, it is very difficult to assess the losses in country like India but personal experience and various reports prioritize spot blotch (Sharma \& Duveiller, 2004), leaf rust and yellow rust with sporadic incidence of powdery mildew as serious diseases for Indian wheat besides the threat of $U g 99$ race of black rust. Spot-blotch concern is increasing day by day and breeding for resistance against this pathogen is difficult due to pathogen adaptation and cultural practices involving use of crop debris, which may act as reservoir hosts. Introduction of resistant varieties is the most-effective and cheapest way to eradicate the disease.

The availability of number of slow ruster lines against leaf rust and their frequent utilization in Indian wheat breeding programme as shown by the presence of $L r 34, L r 13$ and $L r 46$ in number of varieties; the threats to leaf rust probably can be minimized by putting more emphasis on adult plant resistance and slow rusting minor genes. The close association of $L r 34$ and $L r 46$ with $Y r 18$ and $Y r 29$ respectively can prove very effective against prevailing yellow rust races in North-western plain zone. None of the above mentioned genes are present in PBW 343, the most dominating variety in India and adjoining Pakistan under the name Inqlab 91 therefore increase the threat perception against yellow rust and brown rust (Williams et al. 2003; Rosewarne et al. 2006). Coverage of large acreage with single cultivars like PBW343 carrying race specific resistant genes like $Y r 27$, provide an opportunity for faster amplification of matching virulence like $78 \mathrm{~S} 84$, and thereby increasing the threat of epidemic outbreak as it happened in 2008-09. Number of older wheat varieties like HD 2329, HD 2894 
and some of the recently released varieties like HD 2967 and DBW 17 are showing sufficient degree of resistance against 78 S 84 under field conditions and moreover, strains like DBW 17, HD 2894 and HD 2967 are as high yielding as PBW 343 and therefore, can create a mosaic of varieties in North western plain Zone.

Ug99 is race of black rust (Puccinia graminis Pers.: Pers) initially detected in 1999 in Uganda and therefore named so. It quickly spreaded to newer areas and was detected in Kenya in 2002-03, Ethiopia in 2003-04 and last in Iran. Most of the germplasm of CIMMYT was susceptible against this race and therefore, there emerged a challenge to protect wheat crop from this race of black rust fungus. It was able to overcome the resistance imposed by $\operatorname{Sr} 31$ and $\operatorname{Sr} 38$ and its new variant are evolving quite rapidly to combine virulence against many important rust resistant genes. Most of the popular varieties of wheat in India like PBW 343, PBW 373, WH 542, Raj 3765 are susceptible to this race. What is more peculiar about this race is its ability to survive in cold. Conventionally black rust appears quite late in the growing season and therefore, provide a chance to the crop to avoid the loss. However, Ug99 can attack the crop quite early and therefore pose a greater threat than can be assumed from other races of black rust. The faster movement and quick evolution of new variant pose the greatest challenge to the researcher to contain the spread of this disease. Though $U g 99$ or its variant is not available in India, as a preemptive move India has started evaluating its material in Njoro in Kenya in 2005 and found number of varieties/ strains like HD 2781, RL153-2, NI 5439 and HI 8498, suitable for central and peninsular zone where chances of its appearance are more, resistant to $U g 99$ and its variants.

\subsection{Breeding wheat for terminal heat stress and high temperature}

The proximity to the equator exposes much of the wheat in South- East Asia including India to late heat stress particularly at the time of grain filling (Tandon 1994; Rane et al. 2000). Similarly many parts of North-western plain zone including parts of Rajasthan and most parts of Haryana, are exposed to high temperature due to dry winds coming from Thar desert. Higher mean temperature particularly immediately after anthesis reduced the yield significantly (Wardlaw \& Wrigley, 1994). Besides agronomic management, like residue retention on the surface, development of heat tolerant genotypes is the cheapest means of combating the heat and high temperature stress. A number of high yielding genotypes that are able to tolerate high temperature at the time of grain filling are now available as HUW 234, DBW 14, HD 2643 and Raj 3765. Physiological traits associated with high yields should be incorporated in developing lines for adaptation to warmer climates. Late heat tolerance can be incorporated by enhanced membrane thermostability, significant canopy temperature depression, increased stay-green habit and better stem- reserve mobilization rates. However, the more worrying aspect is the fact that late heat, which used to be the problem for north eastern plain zone is now also affecting north-western plain zone and that too in erratic manner. Shuttle breeding i.e evaluating the breeding material alternatively at the locations in north eastern plain and north western plain can come up with the material with heat adaptive traits and fitting in the cropping system and growth duration of Punjab and Haryana.

\subsection{Management technologies including varieties to increase the input use efficiency}

Economic advantage is the key for sustaining the interest of farmers in growing food crops. The profitability of wheat production systems in the high potential environments depends not just on varietal improvement targeted towards yield increases and yield stability but also on crop management technologies for enhancing input efficiency. Inputs that are in particular need of enhanced efficiency are nitrogen, water, power and human labor. Wheat requires a large input of fertilizer to realize maximum yield and nitrogen $(\mathrm{N})$ and phosphorous are the most commonly used fertilizers globally. Crops typically recover less than $50 \%$ of applied nitrogen $(\mathrm{N})$ and potassium $(\mathrm{K})$ fertilizers and less than $10 \%$ of applied phosphorus $(\mathrm{P})$. Un-recovered N, P and K are displaced through leaching; into the water bodies. These nutrient losses arise primarily due to the use of excess inorganic fertilizers, and can further enrich adjacent environments, with a consequent loss of habitats and decline in biodiversity. There are also financial costs involved in the use of fertilizers. Thus, there are environmental, financial and crop quality benefits to reducing reliance on inorganic fertilizers. Thus, there is an urgent need to develop strategies to reduce fertilizer inputs by selecting and/or breeding more nutrient-efficient varieties of crops, through the characterization of the genetics of nutrient-use efficiency. Molecular markers have accelerated plant breeding in a number of areas including biotic (disease and insect) resistance and abiotic (drought, low nitrogen fertilization and frost) tolerance. Marker-based technology has already provided scientists with a powerful approach for identifying and mapping quantitative trait loci (QTL) and would lead to the development of a better understanding of genetic phenomena. Development of wheat varieties with inherently efficient nitrogen and phosphorus through a dedicated breeding programme combined with high yield is the most significant approach. Further mapping a complex trait like nutrient use efficiency may track down the network of genes associated with the trait and may prove helpful in designing newer breeding programmes. 


\subsection{Wide scale utilization of alien translocation to enhance the yield potential}

The role of $1 \mathrm{~B} / 1 \mathrm{R}$ translocation in not only raising the yield potential of wheat through many important wheat varieties like PBW 343, PBW 373, WH 542, CPAN 3004, Raj 3765 and HD 2733, but also stabilizing it at higher level due to resistance it offered against many important diseases like brown rust through $\mathrm{Lr} 26$, yellow rust through $\mathrm{Yr} 9$ and powdery mildew through $P m 8$ is well known and has been the back bone of third spurt in productivity gain in north-western plain zone. The first two were based on Kalyan Sona and HD 2329. Wheat lines bearing $1 \mathrm{~B} / 1 \mathrm{R}$ translocation have better tolerance to abiotic stresses and the gain in yield due to this segment was more in the stress prone areas. With likely uncertainty in production environment due to climate change, exploitation of lines bearing such translocations can provide increased adaptation of changed climatic conditions. Many other translocation lines like 1A/1R have been produced but only few like 7DL.7Ag has been used by the breeders in their programme. Alien translocations confer many insect and disease resistance genes and the aggressive exploitation of these translocation in the breeding programme can produce good segregants as these translocation require proper genetic background for their potential expression and effect on yield.

\subsection{Biotechnological approaches including development of transgenics and marker assisted selection (MAS) for complex traits}

The technological advance has not only improved the understanding of genetic control and regulation of traits but has also widened the scope of its application. The improvement of transformation protocols, development of high-density molecular marker maps (Somers et al. 2004), the cloning of several wheat genes (Peng et al. 1999; Yan et al. 2003), statistical tools for characterization of genotype $\mathrm{x}$ environment interactions (Trethowan et al. 2003b) and virus induced gene silencing systems for candidate gene evaluation (Scofield et al. 2005) have the potential to revolutionize the wheat breeding. Production of transgenic wheat incorporating disease resistance genes is a potent option for preventing yield losses. Transgenic wheat plants with specific differences in their grain quality traits will highly enhance the end-use properties of wheat (He et al. 1999). This needs the application of reliable and robust transformation methods for introduction of additional genes. However, non-acceptance of transgenic wheat by the public is the biggest impediment in the knowledge application. Herbicide resistant transgenic wheats have been developed in India but controversies remain regarding the spread of transgene to wild relatives. Besides ethical issues for non-adoption of genetically modified material, higher costs are also an impediment. Conventional plant breeding has been successful in the past for increasing the yield level significantly and there are no indications of its saturation in the near future. However, to overcome the increased level of barrier for genetic improvement, the success with traditional breeding method is more likely to be economically unviable and unsustainable. The newer tools and technologies like molecular marker technologies provided a range of opportunities to plant breeders to improve their selection efficiency. Marker-assisted selection (MAS) is new technique making use of knowledge generated at genomic level to assist plant breeders in selection of plants with desirable traits. Much of plants hidden potential were unknown in the past as most of the selection were done on the basis of phenotype but MAS hold the potential to unlock the hidden variability for important traits like yield and resistance against biotic and abiotic stresses. Similarly most of the phenotype we observe arises from the interaction between genes, RNA, proteins and environmental signals and therefore breeding techniques have been more successful where single gene harbors the desired trait. MAS on the other hand hold the potential to deal with sets of interacting genes for complex traits. The information generated about the location and numbers of genes controlling the traits of interest through comparative mapping and QTL studies can speed up the end product specific variety. The good news is Triticeae genome is rapidly evolving, and quite heterogeneous ( $\mathrm{Yu}$ et al. 2008) and therefore offers opportunities to the plant breeders to continuously search for novel genetic variation.

Despite all these advantages, there are only very few instances (Cakir et al. 2003a, Kuchel et al. 2007), where the application of MAS for yield improvement has been conclusively established. Continuous improvement in these technologies will make them indispensable in the near future. Marker assisted backcrossing can routinely be integrated in the breeding programme to introgress the different disease and pest resistant genes as well as genes for quality improvement. Marker assisted selection can be very helpful in selection of parental lines for crossing in making complex crosses, particularly where the traits to be transferred is recessively inherited and thus removes the need for progeny testing. With boom and bust cycle associated with all the three rusts, it become imperative to pyramid the number of multiple effective genes in single genetic background, which is impossible without using MAS.

Another area where MAS can be useful in improving the breeding efficiency is the early generation selection. With increasing throughput analysis, large material can be screened by marker assisted selection in the early generation for multiple traits. Lesser and lesser materials, therefore, will be advanced for replicated, multilocaton 
testing, which is more expensive and time consuming. The initial use of MAS in tracking the gene from donor parent is still relevant but selection of background in the absence of sufficient large number of reliable markers and whole genome analysis discourage the use of this technique. However, for most of the complex traits like yield, accurate detection and estimation of QTL effect (Reynolds et al. 2008), undesirable linkage of already identified QTL and differential value of multiple QTL alleles are the issues which are identified a decade ago but are still relevant today. Despite its all advantages, the decision to invest in cutting edge technologies is governed by the availability of resources and economic return offered by the application of these technologies. The traditional plant breeding is largely based on individual skill and has proven its worth over centuries. With abundant trained manpower in breeding crop plants, any investment on newer tools in India at the cost of traditional plant breeding will be less fruitful. Moreover, there seems to be no linkage and exchange of ideas and material between the traditional plant breeders and molecular breeders, and most of hard core wheat breeding programmes have hardly imbibed the knowledge of this technology in India and therefore a strong joint effort by the two will prove more rewarding.

\section{Policy issues needs to be addressed}

In Indian agriculture research system, a vast network of commodity or crop based institutes along with number of state agricultural universities are functional to give specific impetus to the research. With increasing cropping intensity, policy planners and researchers are putting more emphasis on cropping system research. However, most of the research on these aspects is peripheral with little emphasis on integrating these research in the main stream. Breeding programme has rarely been designed to address the issues of cropping system except for some isolated effort on rice- wheat. With changing climatic condition and falling water table, it becomes now evitable to discuss whether in cropping system like rice-wheat, short duration rice varieties are environmentally and economically more sustainable as has been proved with success of short duration rice hybrid PRH 10 and basmati variety Pusa 1121. The area of research on cropping system being new, the results will be slow to come in comparison to strategic research and therefore there is immediate need to protect and revive the confidence of scientist working on system based research. Many a times very good technologies fail to make an impact because end users do not have confidence in the technology as they have neither been consulted nor involved in planning for the strategies. Zero tillage, a very good technology has not been accepted by the farmers largely due to their inherited notion about the tillage and their non involvement in research planning and equipment designing. It is, therefore very important to involve the end users at every stage i.e. started from planning to the testing and evaluation of technologies.

The reasons for non adoption of the new technologies including variety by the farmers needed to be thoroughly studied and policies should be made which lay emphasis on passing sufficient and concise information to the farmers. Many times the reasons are non scientific for instance a variety like HD 2733 developed by IARI, a very high yielding line released for cultivation in North eastern plain zone is not aggressively campaigned for adoption in that region either because the state machinery is ill equipped or not able to appreciate the technology due to some other reasons. Beside, these issues, policies related to introduction of transgenic wheat should be reviewed keeping in view the new tools which pose fewer risks. Similarly linkage between government research and private seed companies should be worked out to make availability of quality seed to the farmers.

\section{References}

Araus, J. L., Slafer, G. A., Reynolds, M. P., \& Royo, C. (2002). Plant breeding and water relations in $\mathrm{C}_{3}$ cereals: What to breed for? Annals of Botany, (London) 89, 925-940.

Cakir, M., Appels, R., Carter, M., Loughman, R., Francki, M., Li, C., Johnson, J., Bhave, M., Wilson, R., McLean, R., \& Barclay, I. (2003a). Accelerated wheat breeding using molecular markers. In: Proceedings of $10^{\text {th }}$ International Wheat Genetics Symposium. Vol.1. Istituto Sperimentale per la Cerealicoltura, Roma, pp. 117-120.

Condon, A. G., Reynolds, M. P., Rebetzke, G. J.,Ginkel, M.V., Richards, R. A., \& Farquhar, G. D. (2005). Using stomatal aperture-related traits to select for high yield potential in bread wheat. Wheat Production in Stressed Environments. Proceedings of the 7th International Wheat Conference, 27 November-2 December, Mar del Plata, Argentina. pp 617-624.

Duveiller, E., Fucikovsky, L., \& Rudolph, K., (eds). (1997). The bacterial diseases of wheat: concepts and methods of disease management, CIMMYT, Mexico, D.F., 78 pp

Dvorak, J., Di Terlizzi, P., Zhang, H. B. \& Resta, P. (1993). The evolution of polyploid wheats: identification of the A genome donor species. Genome, 36, 21-31.

Dvorak, J., Luo, M. C., Yang, Z. L., \& Zhang, H. B. (1998). The structure of the Aegiolops Tauschii gene pool and the evolution of hexaploid wheat. Theoretical and Applied Genetics, 97, 657-670. 
Evans, L.T. (1993). Crop evolution, adaptation and yield. Cambridge, Cambridge University Press.

Falcon, W.P., \& Naylor, R.L. (2005). Rethinking food security for the 21st century'. American Journal of Agricultural Economics, 87 (5), December, 1113-1127.

Fischer, G., Shah, M., \& Van Velthuizen, H. (2002). Climate change and agricultural vulnerability. World summit on sustainable development, Johannesburg.

He, G. Y., Ovidio, R., Anderson, O. D., Fido, R., Tatham, A. S., Jones, H. D., Lazzeri, P. A., \& Shewry, P. R. (1999). Modification of storage protein composition in Transgenic bread wheat. In: wheat gluten, eds. P.R., Shewry \& Arthur,S., Tatham, Royal Society of Chemistry, 81-84.

Hobbs, P. R., \& Morris, M. L. (1996). Meeting South Asia's future food requirements from rice-wheat cropping systems: priority issues facing researchers in the post-green revolution era., NRG Paper 96-01. CIMMYT, Mexico, DF.

Hobbs, P.R. (2001). Tillage and crop establishment in South Asian rice-wheat systems: present and future options. In: Kataki PK (ed) The rice-wheat cropping system of South Asia: efficient production management. Journal of Crop Production, 4, 1-23.

Jain, K. B. L., \& Byerlee, D. (1999). Investment efficiency at the national level: Wheat improvement research in India. In: M.K. Maredia and D. Byerlee (eds.) The global wheat improvement system: Prospects for enhancing efficiency in the presence of spillovers, CIMMYT Research Report No. 5. Mexico, D.F., CIMMYT.

Joshi, A. K., Chand, E. R., Arun, E. B., Singh, R. P., \& Ortiz, R. (2007). Breeding crops for reduced-tillage management in the intensive, rice-wheat systems of South Asia. Euphytica, 153, 135-151.

Kihara, H. (1944). Discovery of the DD-analyzer, one of the ancestors of Triticum vulgare (in Japanese). Agriculture and Horticulture Japan, 19, 889-890.

Kuchel, H., Fox, R., Reinheimer, J., Mosionek, L., Willey, N., Bariana, H., \& Jefferies, S. (2007). The successful application of a marker-assisted wheat breeding strategy. Molecular. Breeding, 20 (4), 295-308.

Matuschke, I., Mishra, R. R. \& Qaim, M. (2007). Adoption and Impact of Hybrid Wheat in India. World Development, 35,1422-1435.

Ogbonnaya, F.C., Halloran, G.M., \& Lagudah, E. S. (2005). D genome of wheat - 60 years on from Kihara, Sears and McFadden. In: Tsunewaki K, ed. Frontiers of Wheat Bioscience, the 100th Memorial Issue of Wheat Information Service, Kihara Memorial Foundation for the dvancement of Life Sciences, Yokohama, Japan, 205-220.

Peng, J. R., Richards, D. E., Hartley, N. M., Murphy, G. P., Devos, K. M., \& Flintham J. E. (1999). 'Green revolution' genes encode mutant gibberellin response modulators. Nature, 400, 256-261.

Rajaram, S., Borlaug, N. E., \& Van Ginkel, M. (2002). CIMMYT international wheat breeding. In: Curtis, B.C., Rajaram, S., Gomez, Macpherson, H. (eds). Bread wheat improvement and production. FAO, Rome, pp $103-117$.

Rane, J., Shoran, J., \& Nagarajan, S. (2000). Heat stress environments and impact on wheat productivity in India:Guestimate of losses. Indian Wheat News Letter, 6(1), 5-6.

Rejesus, R. M., Heisey, P. W., \& Smale, M. (1999). Sources of Productivity Growth in Wheat: A Review of Recent Performance and Medium to Long-Term Prospects. CIMMYT Economics Working Paper 99-05. CIMMYT, Mexico, D.F.

Reynolds, M. P., Dixon, J., Ammar, K., Kosina, P. \& Braun, H.-J. (2008b). Stakeholders' priorities for internationally-coordinated wheat research. In :Reynolds M.P., J. Pietragalla, and H.-J. Braun, (eds) International Symposium on Wheat Yield Potential: Challenges to International Wheat Breeding. Mexico, D.F.: CIMMYT.

Reynolds, M.P., Hobbs, P., Ortiz, R., Pietragalla, J., \& Braun, H.-J. (2008a). International Wheat Improvement: Highlights from an Expert Symposium. In Reynolds M.P., J. Pietragalla, and H.-J. Braun, (eds) International Symposium on Wheat Yield Potential: Challenges to International Wheat Breeding. Mexico, D.F.: CIMMYT.

Rosewarne, G. M., Singh, R. P., Huerta-Espino, J., William, H. M., Bouchet, S., Cloutier, S., McFadden, H., \& Lagudah, E.S. (2006). Leaf tip necrosis, molecular markers and b1-proteasome subunits associated with the slow rusting resistance genes Lr46/Yr29. Theoretical and Applied Genetics, 112, 500-508.

Sayre, K. D. (2002). Management of irrigated wheat. In: Curtis B.C., Rajaram S., Gomez Macpherson H. (eds) Bread wheat: improvement and production. Food and Agriculture Organization, Rome, Italy, pp 395-406. 
Scofield, S. R., Huang, L., Brandt, A. S, \& Gill, B. S. (2005). Development of a Virus-Induced Gene-Silencing system for hexaploid wheat and its use in functional analysis of the $\operatorname{Lr} 21$-mediated leaf rust resistance pathway. Plant Physiology, 138, 2165- 2173.

Sharma, R. C., \& Duveiller, E. (2004). Effect of Helminthosporium leaf blight on the performance of timely and late seeded wheat under optimal and stressed levels of soil fertility and soil moisture. Field Crops Research, 89, $205-218$.

Shiklomanov, A., \& Rodda, J. C. (2003). Summary of the Monograph 'World Water Resources at the beginning of the $21^{\text {st }}$ Century', prepared in the framework of IHP UNESCO. 1999. [Online] Available: http://webworld.unesco.org/water/ihp/db/shiklomanov/ summary/html/summary.html.

Singh, S. S., Sharma, J. B., Sharma, D. N., \& Chand, N. (2005). Developments in Plant Breeding In: Wheat Production in Stressed Environments. Proceedings of the 7th International Wheat Conference, 27 November-2 December, Mar del Plata, Argentina. pp 625-631.

Slafer, G. A., Araus, J. L., Royo, C., \& DelMoral, L. F. G. (2005). Promising eco-physiological traits for genetic improvement of cereal yields in Mediterranean environments. Annals of Applied Biology, 146 (1), 61-70.

Slafer, G., Araus, J. L., \& Richards, R.A. (1999). Promising traits for future breeding to increase wheat yield. p. 379-415. In E.H. Satorre and G.A. Slafer (ed.) Wheat ecology and physiology of yield determination, Food Products Press, New York.

Somers, D. J., Isaac, P. \& Edwards, K. (2004). A high-density microsatellite consensus map for bread wheat (Triticum aestivum L.). Theoretical and Applied Genetics, 109 (6), 1105-1114.

Swaminathan, M. S. (2006). An Evergreen Revolution. Crop Science, 46(5), 2293-2303.

Tandon, J. P. (1994). Wheat cultivation, research, organistion and production technology in the hot dry regions of India In: D.A. Saunders and G. P. Hettel (eds). Wheat in heat stressed environments:Irrigated Dry Areas and Rice Farming Systems. Proceedings of the International Conference, Wheat in Hot, Dry, irrigated Environments, Mexico, D.F. CIMMYT.

Terachi, T., Ogihara, Y., \& Tsunewaki, K. (1988). Proceedings of International wheat Genetics Symposium, $7^{\text {th }}$, $1,785-789$.

Trethowan, R. \& Reynolds, M. (2005). Drought resistance: genetic approaches for improving productivity under stress. In: Proceedings of the 7th international wheat conference, 27 November-2 December, Mar del Plata, Argentina.

Trethowan, R.M., Van Ginkel, M., Ammar, K., Crossa, J., Payne, T.S., Cukadar, B., Rajaram, S., \& Hernandez, E. (2003b). Associations among twenty years of international bread wheat yield evaluation environments., Crop Science, 43, 1698-1711.

Wardlaw, I. F., \& Wrigley, C. W. (1994). Heat tolerance in temperate cereals: An overview. Australian Journal of Plant Physiology, 21, 695-703.

Watt, M., Kirkegaard, J. A., \& Rebetzke, G. J. (2005). A wheat genotype developed for rapid leaf growth copes well with the physical and biological constraints of unplowed soil. Funcional and Plant Biology, 32, 695-706.

Wilcoxson, R. D., \& Saari, E. E. (1996). Bunt and smut diseases of wheat concepts and methods of disease management. CIMMYT, Mexico D.F.

Williams, C. E., Collier, C. C., Sardesai, N., Ohm, H. W., \& Cambron, S. E. (2003). Phenotypic assessment and mapped markers for H31, a new wheat gene conferring resistance to Hessian fly (Diptera: Cecidomyiidae). Theoretical and Applied Genetics, 107, 1516-1523.

Yan, L., Loukoianov, A., Tranquilli, G., Helguera, M., Fahima T., \& Dubcovsky, J. (2003). Positional cloning of the wheat vernalization gene VRN1., Proceedings of National Academy of Sciences, USA, 100, 6263-6268.

Yu, H., Fan, X., Zhang, C., Ding, C. \& Wang, Z. (2008). Phylogenetic relationships of species in Pseudogroegneria (Poaceae: Triticeae) and related genera inferred from nuclear rDNA ITS (internal transcribed spacer sequences). Biologia, 64(4), 498-505. 